PRINT ISSN: $2348-7437$

ONLINE ISSN: $2454-9533$

\title{
Contents
}

\section{International Journal of Information Science and Computing}

Volume 7, No. 1, June 2020

Agricultural Informatics: The emerging field with references to potentiality as Post Doctoral Certificate Programs

P.K. Paul, Anil Bhuimali, R.R. Sinha K.S. Tiwary, Pappachan Baby and G.C. Deka

The Impact of Virtual Currencies on Money, Banking and Economic Market:

An Analysis and Overview of Modern Economics

Abdul Rahiman Zubair Kotikulam and Shanavas Moosafintavida

Cloud Computing in Agricultural Development of Rural India

Subhendu Chatterjee

The Multiplier Effect of Applied Machine Learning Technology in Modern Healthcare

Abhijit Bandyopadhyay 